\title{
Optimization of Conductivity and Transparency in Amorphous In-Zn-O Transparent Conductors
}

Conference Paper NREL/CP-520-42546

May 2008

\section{Preprint}

J. Perkins, J. Berry, M. van Hest, J. Alleman, M. Dabney, L. Gedvilas, and D.S. Ginley National Renewable Energy Laboratory

A. Leenheer and R. O'Hayre

Colorado School of Mines

Presented at the 33rd IEEE Photovoltaic Specialists Conference San Diego, California

May 11-16, 2008

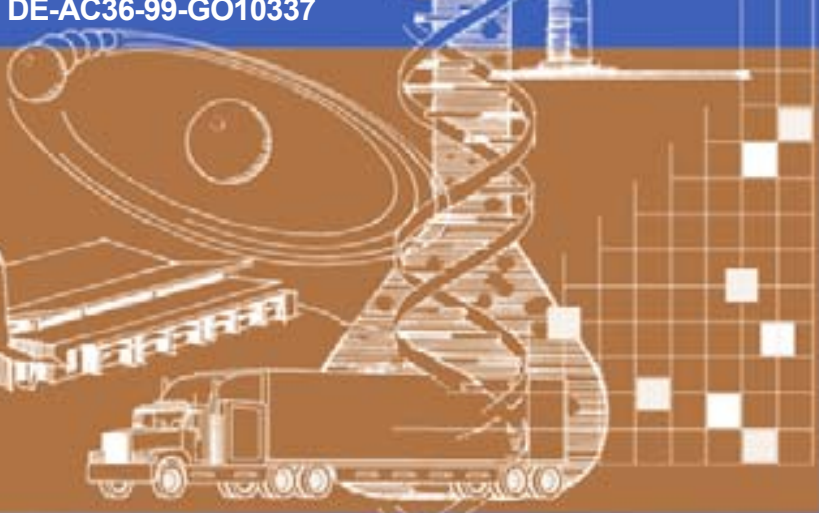




\section{NOTICE}

The submitted manuscript has been offered by an employee of the Midwest Research Institute (MRI), a contractor of the US Government under Contract No. DE-AC36-99G010337. Accordingly, the US Government and MRI retain a nonexclusive royalty-free license to publish or reproduce the published form of this contribution, or allow others to do so, for US Government purposes.

This report was prepared as an account of work sponsored by an agency of the United States government. Neither the United States government nor any agency thereof, nor any of their employees, makes any warranty, express or implied, or assumes any legal liability or responsibility for the accuracy, completeness, or usefulness of any information, apparatus, product, or process disclosed, or represents that its use would not infringe privately owned rights. Reference herein to any specific commercial product, process, or service by trade name, trademark, manufacturer, or otherwise does not necessarily constitute or imply its endorsement, recommendation, or favoring by the United States government or any agency thereof. The views and opinions of authors expressed herein do not necessarily state or reflect those of the United States government or any agency thereof.

Available electronically at http://www.osti.gov/bridge

Available for a processing fee to U.S. Department of Energy and its contractors, in paper, from:

U.S. Department of Energy

Office of Scientific and Technical Information

P.O. Box 62

Oak Ridge, TN 37831-0062

phone: 865.576 .8401

fax: 865.576 .5728

email: mailto:reports@adonis.osti.gov

Available for sale to the public, in paper, from:

U.S. Department of Commerce

National Technical Information Service

5285 Port Royal Road

Springfield, VA 22161

phone: 800.553 .6847

fax: 703.605.6900

email: orders@ntis.fedworld.gov

online ordering: http://www.ntis.gov/ordering.htm 


\title{
OPTIMIZATION OF CONDUCTIVITY AND TRANSPARENCY IN AMORPHOUS IN-ZN-O TRANSPARENT CONDUCTORS
}

\author{
John Perkins, Joseph Berry, Maikel van Hest, Jeff Alleman, Matthew Dabney, Lynn Gedvilas, David S. Ginley \\ National Renewable Energy Laboratory, 1617 Cole Blvd., Golden, CO 80401
}

Andrew Leenheer and Ryan O'Hayre

Colorado School of Mines, Golden, CO 80401

\begin{abstract}
Amorphous mixed metal oxide TCOs are of increasing interest due to the excellent opto-electronic properties and smoothness $\left(R_{R M S}<0.5 \mathrm{~nm}\right.$ ) obtained for sputtered films deposited at less than $100{ }^{\circ} \mathrm{C}$. In particular, for amorphous $\mathrm{In}-\mathrm{Zn}-\mathrm{O}$ (a-IZO) films grown from a ceramic target with 10 wt. $\% \mathrm{ZnO}$ in $\ln _{2} \mathrm{O}_{3}$, the current industry standard, conductivities $\sigma \geq 2500 \mathrm{~S} / \mathrm{cm}$ are common. Here, we have investigated the combined materials phase space of oxygen stoichiometry and metals composition (In: $\mathrm{Zn}$ ratio) and made two key discoveries. First, that high conductivity a-IZO thin films can be made with substantially less indium provided that a corresponding change is also made in the oxygen content. And second, that for all compositions of a-IZO, the electron mobility $(\mu)$ and carrier concentration $(\mathrm{N})$ fall on a single common curve when plotted as $\mu$ vs $N$.
\end{abstract}

\section{INTRODUCTION}

Transparent conducting oxides (TCOs) can serve a variety of important functions in thin film photovoltaics such as transparent electrical contacts, antireflection coatings and chemical barriers [1]. An area of particular interest and active development is amorphous mixed metal oxide transparent conductors which can be grown by sputtering at low, or even ambient, temperature. For example, amorphous In-Zn-O (a-IZO) films grown from a ceramic target with 10 wt. $\% \mathrm{ZnO}$ in $\ln _{2} \mathrm{O}_{3}$, the current industry standard, commonly have conductivities $\sigma \geq 2500$ $\mathrm{S} / \mathrm{cm}$ and are extremely smooth as well with $\mathrm{R}_{\mathrm{RMS}}<0.5$ $\mathrm{nm}[2,3]$. Here, we report on two experiments two experiments aimed at determining the relative roles of metals and oxygen stoichiometries on the opto-electronic properties of a-IZO thin films.

\section{EXPERIMENTAL APPROACH}

First, using co-sputtering from $\mathrm{In}_{2} \mathrm{O}_{3}$ and $\mathrm{ZnO}$ targets, compositional gradient samples spanning the amorphous composition range $(50-85$ at. $\%$ In) were deposited at a substrate heater temperature $\mathrm{T}_{\mathrm{S}}=100{ }^{\circ} \mathrm{C}$ in Ar containing $0,2,4$ or $6 \% \mathrm{O}_{2}$ onto 2"x2" Corning 1737 glass substrates. For each composition gradient sample, 11 spots were measured along the composition gradient to obtain data for different metals compositions. The typical measurement spot size is $\sim 1 \mathrm{~mm}$. X-ray diffraction was used to determine if the samples were amorphous or crystalline. A mapping 4-point probe system was used to determine the sheet resistance. Optical reflection and transmission spectra were measured from $300-1100 \mathrm{~nm}$ using fiber optically coupled CCD array spectrometers. The sample thickness was determined on a spot by spot basis from the thin film interference oscillations in the reflection and transmission spectra [4].

\section{RESULTS AND DISCUSSION}

Figure 1 uses a color intensity scale to show the conductivity of a-IZO as a function of both the oxygen content of the sputter gas (left axis) and the relative metals composition (bottom axis). Yellow spots indicate a high conductivity, $\sigma>2000 \mathrm{~S} / \mathrm{cm}$. Starting from the bottom of the graph, a band of high conductivity angles up and to the right. The solid black line shows the ridge of maximum conductivity. The fact that this line runs diagonally in this $\left(\mathrm{O}_{2}, \% \mathrm{In}\right)$ plot shows that the optimization of conductivity in a-IZO is a coupled process with the best metals composition depending upon the oxygen content of the sputter gas.

In addition to conductivity, transparency is a critical property for thin film transparent conductors. Figure 2

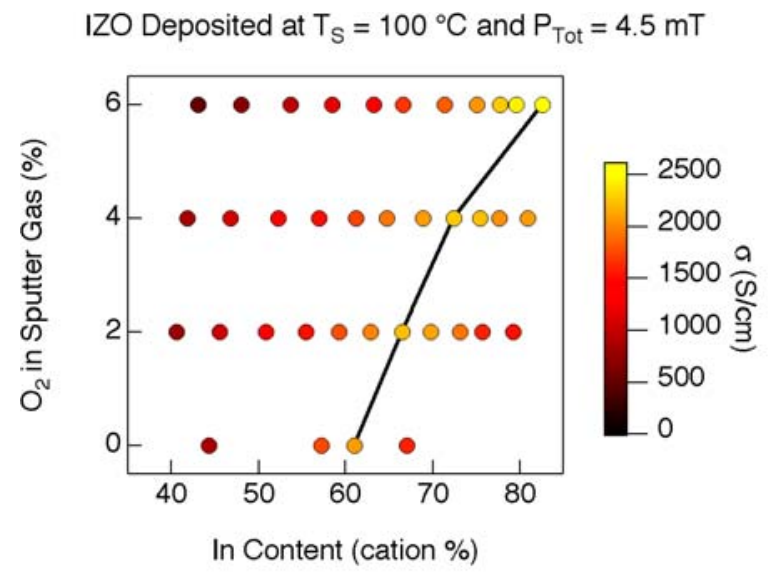

Fig. 1: Conductivity of as-deposited IZO as a function of oxygen content in the sputter gas (left axis) and relative metals composition (bottom axis). 


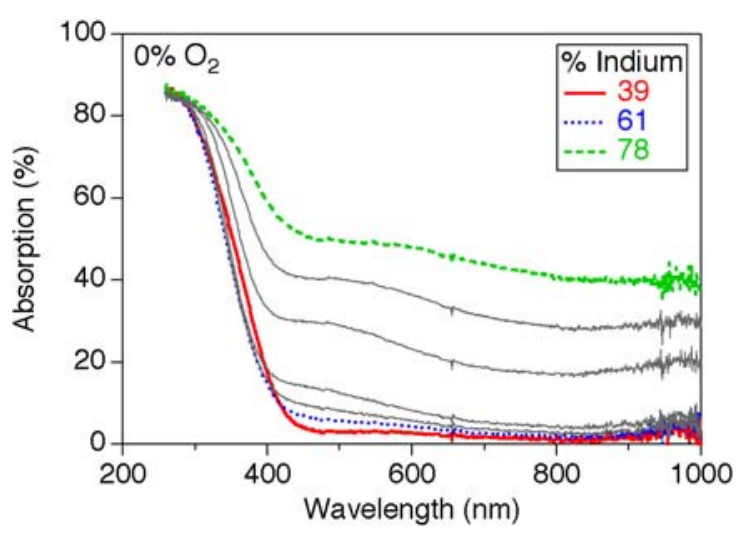

Fig. 2: Optical absorption spectra of IZO samples with varying In content. All samples grown in pure $\mathrm{Ar}$ $\left(0 \% \mathrm{O}_{2}\right)$

shows optical absorption spectra for several representative a-IZO with differing metals compositions but all grown in pure $\operatorname{Ar}\left(0 \% \mathrm{O}_{2}\right)$. The a-IZO samples with 39 cation $\%$ In (red line) and 61 cation\% In (dashed blue line) show almost no absorption for wavelengths longer than about $450 \mathrm{~nm}$. However, for the a-IZO samples with higher indium content, a nearly wavelength independent absorption increases with increasing indium content. For the sample with 78 cation $\%$ indium, the visible wavelength absorption is nearly $50 \%$. Examination of the absorption spectra for a-IZO samples grown in 2 to $6 \% \mathrm{O}_{2}$ (not shown) show that this broad visible wavelength absorption occurs when the relative indium content is higher that the indium content to obtain the best conductivity for the given amount of oxygen used (see Figure 1).

Subsequently, constant composition IZO films were sputter deposited onto ambient temperature fused silica substrates from single composition targets with $x=0.6$, $0.7,0.8$ and $0.84\left(\ln _{x} Z_{n_{1-x}} O_{y}\right)$. The oxygen content of the Ar sputter gas was varied from 0 to $10 \%$, yielding a varia-

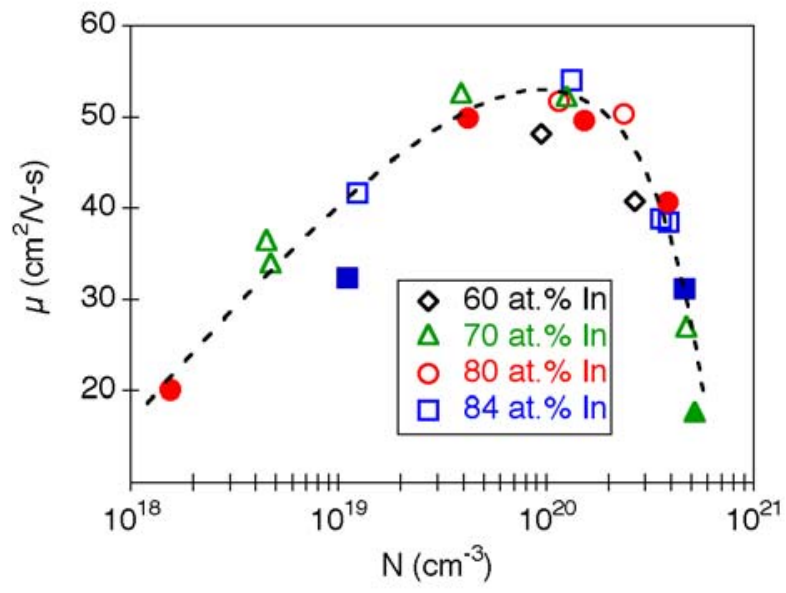

Fig. 3: Mobility vs. carrier concentration for IZO samples grown from single fixed composition sputter targets as indicated in the legend. tion in the conductivity from $\sigma \approx 2 \times 10^{3} \mathrm{~S} / \mathrm{cm}$ down to $\sigma \approx$ $10^{-6} \mathrm{~S} / \mathrm{cm}$. For these samples, additional Hall effect measurements were done to determine the carrier concentration $(\mathrm{N})$ and electron mobility $(\mu)$. Figure 3 shows the mobility as a function of the carrier concentration for the a-IZO samples with $\mathrm{N} \geq 10^{18} / \mathrm{cm}^{3}$. Surprisingly, for all these a-IZO samples, the mobility as a function of the carrier concentration is given by a common curve, independent of the differing metals compositions [5]. This supports the results shown in Figure 1 . At $\mathrm{N} \approx 10^{20} / \mathrm{cm}^{-3}$, the mobility maximum with $\mu \approx 50 \mathrm{~cm}^{2} / \mathrm{V}-\mathrm{s}$, the mobility increased upon cooling to $100 \mathrm{~K}$ indicating metallic conduction for the highest mobility a-IZO materials. At low carrier concentration, $\mathrm{N}<10^{19} / \mathrm{cm}^{3}$, the mobility is thermally activated and at very high carrier concentration, $\mathrm{N} \approx$ $5 \times 10^{20} / \mathrm{cm}^{3}$, the mobility is nearly temperature independent suggestive of screened ionized impurity scattering.

\section{SUMMARY}

In summary, amorphous In-Zn-O (a-IZO) thin film transparent conductors with good TCO properties can be easily deposited at near-ambient temperatures. The aIZO thin films are also extremely flat. Taken together, these attributes make sputtered a-IZO thin film TCOs an attractive choice for many PV applications.

This work was supported by the U.S. Department of Energy under Contract No. DE-AC36-99G010337 with the National Renewable Energy Laboratory.

\section{REFERENCES}

[1] D.S. Ginley and C. Bright, "Transparent Conducting Oxides", MRS Bulletin 25, 2000, pp. 15.

[2] M.P. Taylor, D.W. Readey, C.W. Teplin, M.F.A.M. Van Hest, J.L. Alleman, M.S. Dabney, L.M. Gedvilas, B.M. Keyes, B. To, J.D. Perkins and D.S. Ginley, "The electrical, optical and structural properties of $\ln _{\mathrm{x}} \mathrm{Zn}_{1-\mathrm{x}} \mathrm{O}_{\mathrm{y}}(0<=\mathrm{x}$ $<=1$ ) thin films by combinatorial techniques.", Measurement Science and Technology 16, 2005, pp. 90.

[3] T. Minami, T. Kakumu, Y. Takeda and S. Takata, "Highly transparent and conductive $\mathrm{ZnO}-\mathrm{In}_{2} \mathrm{O}_{3}$ thin films prepared by dc magnetron sputtering", Thin Solid Films 291, 1996, pp. 1-5.

[4] J.D. Perkins, C.W. Teplin, M. Van Hest, J.L. Alleman, X. Li, M.S. Dabney, B.M. Keyes, L.M. Gedvilas, D.S. Ginley, Y. Lin and Y. Lu, "Optical analysis of thin film combinatorial libraries", Applied Surface Science 223, 2004, pp. 124-132.

[5] A.J. Leenheer, J.D. Perkins, M. Van Hest, J.J. Berry, R.P. O'hayre and D.S. Ginley, "General mobility and carrier concentration relationship in transparent amorphous indium zinc oxide films", Physical Review B 77, 2008, 115215 


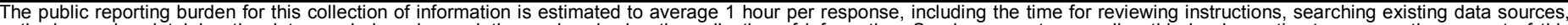

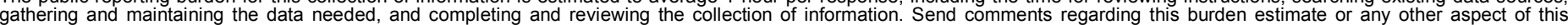

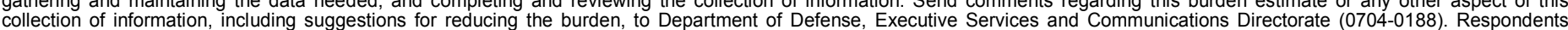

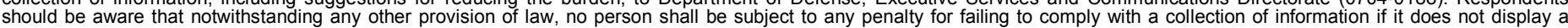

shrild be aware that notwithstanding

PLEASE DO NOT RETURN YOUR FORM TO THE ABOVE ORGANIZATION.

\section{REPORT DATE (DD-MM-YYYY) May 2008 \\ 2. REPORT TYPE \\ Conference Paper}

4. TITLE AND SUBTITLE

Optimization of Conductivity and Transparency in Amorphous

In-Zn-O Transparent Conductors: Preprint
3. DATES COVERED (From - To) 11-16 May 2008

5a. CONTRACT NUMBER

DE-AC36-99-G010337

5b. GRANT NUMBER

5c. PROGRAM ELEMENT NUMBER

5d. PROJECT NUMBER

NREL/CP-520-42546

5e. TASK NUMBER

PVA74201

5f. WORK UNIT NUMBER
7. PERFORMING ORGANIZATION NAME(S) AND ADDRESS(ES)

National Renewable Energy Laboratory

1617 Cole Blvd.

Golden, CO 80401-3393
8. PERFORMING ORGANIZATION REPORT NUMBER

NREL/CP-520-42546

9. SPONSORING/MONITORING AGENCY NAME(S) AND ADDRESS(ES)

10. SPONSOR/MONITOR'S ACRONYM(S) NREL

11. SPONSORING/MONITORING AGENCY REPORT NUMBER

12. DISTRIBUTION AVAILABILITY STATEMENT

National Technical Information Service

U.S. Department of Commerce

5285 Port Royal Road

Springfield, VA 22161

13. SUPPLEMENTARY NOTES

14. ABSTRACT (Maximum 200 Words)

Amorphous mixed metal oxide TCOs are of increasing interest due to the excellent opto-electronic properties and smoothness (RRMS $<0.5 \mathrm{~nm}$ ) obtained for sputtered films deposited at less than $100{ }^{\circ} \mathrm{C}$. In particular, for amorphous In-Zn-O (a-IZO) films grown from a ceramic target with 10 wt. \% ZnO in In2O3, the current industry standard, conductivities $\sigma \geq 2500 \mathrm{~S} / \mathrm{cm}$ are common. Here, we have investigated the combined materials phase space of oxygen stoichiometry and metals composition (In:Zn ratio) and made two key discoveries. First, that high conductivity a-IZO thin films can be made with substantially less indium provided that a corresponding change is also made in the oxygen content. And second, that for all compositions of a-IZO, the electron mobility ( $\mu$ ) and carrier concentration $(\mathrm{N})$ fall on a single common curve when plotted as $\mu$ vs $N$.

15. SUBJECT TERMS

PV; amorphous silicon; transparent conducting oxides; electrical contacts; antireflecftion coatings; chemical barriers; X-ray diffraction; thin film

\begin{tabular}{|c|c|c|c|c|}
\hline \multicolumn{3}{|c|}{ 16. SECURITY CLASSIFICATION OF: } & \multirow{2}{*}{$\begin{array}{l}\text { 17. LIMITATION } \\
\text { OF ABSTRACT } \\
\text { UL }\end{array}$} & \multirow{2}{*}{$\begin{array}{l}\text { 18. NUMBER } \\
\text { OF PAGES }\end{array}$} \\
\hline $\begin{array}{l}\text { a. REPORT } \\
\text { Unclassified }\end{array}$ & $\begin{array}{l}\text { b. ABSTRACT } \\
\text { Unclassified }\end{array}$ & $\begin{array}{l}\text { c. THIS PAGE } \\
\text { Unclassified }\end{array}$ & & \\
\hline
\end{tabular}
19b. TELEPHONE NUMBER (Include area code) 